\title{
NORMATIVAS OFICIAIS PARA A EDUCAÇÃO INFANTIL BRASILEIRA: DESENVOLVIMENTO INFANTIL E EFETIVAÇÃO DA EDUCAÇÃ̃O INCLUSIVA
}

\author{
NORMATIVAS OFICIALES PARA LA EDUCACIÓN INFANTIL BRASILEÑA: \\ DESARROLLO INFANTIL Y EFICACIA DE LA EDUCACIÓN INCLUSIVA
}
OFFICIAL REGULATIONS FOR BRAZILIAN CHILDREN EDUCATION: CHILD DEVELOPMENT AND EFFECTIVENESS OF INCLUSIVE EDUCATION

\author{
Débora Ribeiro da Silva Campos FOLHA ${ }^{1}$ \\ Maysa Marinho Antunes RAMOS ${ }^{2}$ \\ Patrícia Carla de Souza DELLA BARBA ${ }^{3}$
}

RESUMO: O estudo ora apresentado teve como objetivo analisar as normativas oficiais brasileiras alusivas à Educação Infantil, no que se refere à concepção de desenvolvimento infantil adotada e aos pressupostos para o provimento de práticas inclusivas para esse nível educacional, bem como discutir a concepção de desenvolvimento infantil adotada nas políticas públicas de Educação Infantil e as possíveis reverberações desta na implementação de práticas inclusivas. Para tanto, foi realizada uma revisão de literatura com base no levantamento das normativas oficiais que vêm orientando a Educação Infantil inclusiva no Brasil. Os resultados apontam para a existência de um arcabouço legal expressivo no que se refere à Educação Infantil, porém ainda muito incipiente sob a ótica da inclusão, secundarizada nos documentos e, por conseguinte, nas práticas vigentes.

PALAVRAS-CHAVE: Normativas. Educação Infantil. Desenvolvimento infantil. Educação inclusiva.

RESUMEN: El estudio presentado presentó como objetivo analizar las normativas oficiales brasileñas alusivas a la educación infantil, en lo que se refiere a la concepción de desarrollo infantil adoptado y los presupuestos para la provisión de prácticas inclusivas para ese nivel educativo, así como discutir la concepción de desarrollo infantil adoptada en las políticas públicas de educación infantil y las posibles reverberaciones de ésta en la implementación de prácticas inclusivas. Para ello se realizó una revisión de literatura basada en el levantamiento de las normativas oficiales que vienen orientando la educación infantil

\footnotetext{
${ }^{1}$ Universidade Federal de São Carlos (UFSCar), São Carlos - SP - Brasil. Doutoranda do Programa de PósGraduação em Terapia Ocupacional da UFSCar. Professora Assistente III do Departamento de Terapia Ocupacional da Universidade do Estado do Pará - UEPA. ORCID: 〈https://orcid.org/0000-0002-0743-603X〉. E-mail todeboracampos@gmail.com

${ }^{2}$ Universidade Federal de São Carlos (UFSCar), São Carlos - SP - Brasil. Mestre pelo Programa de PósGraduação em Terapia Ocupacional. ORCID: 〈https://orcid.org/0000-0003-0158-256X〉. E-mail maysamarinhoramos@gmail.com

${ }^{3}$ Universidade Federal de São Carlos (UFSCar), São Carlos - SP - Brasil. Docente do curso de graduação em Terapia Ocupacional da UFSCar e do Programa de Pós-Graduação em Terapia Ocupacional. ORCID: <http://orcid.org/0000-0002-7893-8133>. E-mail patriciadellabarba@yahoo.com.br
} 
inclusiva en Brasil. Los resultados apuntan a la existencia de un marco legal expresivo en lo que se refiere a la educación infantil, pero aún muy incipiente bajo la óptica de la inclusión, secundada en los documentos y, por consiguiente, en las prácticas vigentes.

PALABRAS CLAVE: Normativas. Educación infantil. Desarrollo infantil. Educación inclusiva.

ABSTRACT: The purpose of this study was to analyze the official Brazilian norms referring to early childhood education, with regard to the conception of adopted child development and the assumptions for the provision of inclusive practices for this educational level, as well as to discuss the conception of adopted child development in the public policies of early childhood education and its possible reverberations in the implementation of inclusive practices. For that, a literature review was carried out based on the survey of the official norms that have been guiding inclusive child education in Brazil. The results point to the existence of an expressive legal framework with regard to early childhood education, but still very incipient from the point of view of inclusion, secondarily in the documents and, therefore, in the current practices.

KEYWORDS: Normativas. Child education. Child development. Inclusive education.

\section{Introdução}

A Educação Infantil corresponde à primeira etapa da educação básica e, na realidade brasileira, durante muito tempo, foi considerada uma função estritamente familiar. Por isso, a educação formal das crianças pequenas, até pouco tempo, não era alvo de preocupações e, consequentemente, de políticas públicas (KUHLMANN JR, 2000; FRANCISCHINI; SILVA, 2012; OLIVEIRA, 2008).

Do ponto de vista sociológico, “[...] a infầncia é concebida como uma categoria social do tipo geracional por meio da qual se revelam as possibilidades e os constrangimentos da estrutura social” (SARMENTO, 2005, p. 363). Assim, na medida em que se concebe um "status social" à infância, ações que visam protegê-la tornam-se inerentes e benéficas para todos.

O conceito de criança adotado neste artigo baseia-se na definição preconizada pelo Estatuto da Criança e do Adolescente (BRASIL, 1990), que considera "criança" toda pessoa com até onze anos de idade, concebida como sujeito de direitos e para a qual deve ser assegurada proteção integral, oportunidades e facilidades, a fim de lhes facultar o pleno desenvolvimento físico, mental, moral, espiritual e social, em condições de liberdade e de dignidade. O termo "infância" também será utilizado, visto que a infância é uma condição da 
criança, assim como uma produção histórica dependente da cultura e contexto desta (FRANCISCHINI; SILVA, 2012).

Assim, a concepção de criança enquanto sujeito de direitos passa a nortear as normativas oficiais brasileiras, ao mesmo tempo em que a Educação Infantil começa a ser alvo de políticas e prescrições educacionais oficiais. Considera-se normativas, neste estudo, todo documento que estabelece ou versa sobre normas definidas pelo Poder Legislativo, como leis, decretos, resoluções, portarias, dentre outros.

Sabe-se que a existência de documentos prescritivos não é suficiente, embora seja importante para subsidiar iniciativas públicas e incentivar a adoção de práticas pautadas na justiça e na equidade social (CAMPOS, 2009). Nesse sentido, este artigo enfatiza, enquanto problemática, as proposições legais vinculadas à Educação Infantil na perspectiva da Educação Inclusiva.

Para tanto, destacam-se três argumentos centrais que estruturam as motivações e a justificativa para este estudo. O primeiro diz respeito ao histórico da Educação Infantil, que por muito tempo foi negligenciada enquanto serviço efetivamente educacional, por seu surgimento atrelado à inserção das mulheres no mercado de trabalho e o caráter assistencialista que foi assumido no início das práticas. No contexto brasileiro, apenas na década de 1990 a Educação Infantil foi regulamentada enquanto etapa oficialmente vinculada à Educação Básica, possuindo definições e preconizações legais, porém, a existência de políticas voltadas para o campo não tem parecido ser suficiente para garantir a oferta de serviços a contento (KUHLMANN JR, 2000; FRANCISCHINI; SILVA, 2012). O segundo argumento refere-se às especificidades sobre a Educação Inclusiva na Educação Infantil, visto que muitas normativas oficiais referentes à Educação Inclusiva não especificam ações e serviços voltados à população da Educação Infantil, o que produz o risco de dupla interpretação, com o pensamento de que a mesma não se aplica a este nível educacional. Ainda que se diga que as normativas devem ser equivalentes para todos os níveis educacionais, o provimento de serviços no âmbito da Educação Infantil ainda fica muito aquém do que é previsto oficialmente. O terceiro argumento refere-se à concepção de desenvolvimento infantil presente nas normativas oficiais que regem o campo da Educação Infantil.

Desse modo, este estudo pretendeu responder às seguintes questões norteadoras: 1) Qual a concepção de desenvolvimento infantil presente nas normativas oficiais brasileiras 
alusivas à Educação Infantil? e 2) Quais os pressupostos legais para a implementação de práticas inclusivas na Educação Infantil, segundo as normativas oficiais brasileiras?

Para tanto, os objetivos foram: 1) Analisar as normativas oficiais brasileiras alusivas à Educação Infantil, no que se refere à concepção de desenvolvimento infantil adotada e aos pressupostos para o provimento de práticas inclusivas neste nível educacional; e 2) Discutir os pressupostos legais para a implementação de práticas inclusivas na Educação Infantil, segundo as normativas oficiais brasileiras.

\section{Método}

Este estudo adota abordagem qualitativa e trata-se de uma revisão de literatura baseada em um levantamento das normativas oficiais que regem a Educação Infantil no Brasil, na perspectiva da Educação Inclusiva.

A busca das normativas foi realizada no site do Ministério da Educação e Cultura (MEC, disponível em: http://portal.mec.gov.br/pdde/195-secretarias-112877938/sebeducacao-basica-2007048997/12579-educacao-infantil) e a sistematização dos dados foi realizada em uma planilha de catalogação das normativas oficiais da Educação Infantil na perspectiva inclusiva, no programa Word for Windows.

A busca foi realizada por duas pesquisadoras, responsáveis por preencher a referida planilha, estruturada em quatro eixos: 1) A referência completa da normativa; 2) O objetivo da mesma; 3) Trechos das normativas que respondiam às questões norteadoras deste estudo e 4) Reflexões acerca dos trechos destacados. Posteriormente à busca e sistematização, os dados da planilha foram organizados e discutidos à luz de referenciais teóricos pertinentes, o que se encontra apresentado na próxima seção.

\section{Resultados e discussão}

Os resultados deste estudo apontaram para a existência de normativas destinadas a instituir diretrizes para o oferecimento de práticas de Educação Infantil enquanto um nível educacional. Apesar disso, as legislações mostraram-se ainda vagas ou insuficientes no que diz respeito à menção à Educação Infantil na perspectiva inclusiva.

O Quadro 1 lista as normativas oficiais analisadas neste estudo, contendo a referência e o objetivo de cada uma. O critério de inclusão adotado baseou-se no atendimento às questões norteadoras deste estudo, de modo que foram analisadas as normativas que versam 
sobre a concepção de desenvolvimento infantil adotada e sobre os pressupostos legais para a implementação de práticas inclusivas na Educação Infantil.

Quadro 1 - Normativas oficiais derivadas do levantamento realizado e analisadas neste estudo, com os respectivos objetivos

\begin{tabular}{|c|c|}
\hline NORMATIVA & OBJETIVO \\
\hline $\begin{array}{l}\text { Lei } \mathrm{n}^{\circ} \text {.9.394, de } 20 \text { de dezembro } \\
\text { de } 1996 \text { (BRASIL, 1996) }\end{array}$ & Estabelecer as diretrizes e bases da educação nacional. \\
\hline $\begin{array}{l}\text { Referencial curricular nacional } \\
\text { para a Educação Infantil - Volume } \\
\text { I (BRASIL, 1998a) }\end{array}$ & $\begin{array}{l}\text { Auxiliar a realização do trabalho educativo diário junto às } \\
\text { crianças pequenas. }\end{array}$ \\
\hline $\begin{array}{l}\text { Referencial curricular nacional } \\
\text { para a Educação Infantil - Volume } \\
\text { II (BRASIL, 1998b) }\end{array}$ & $\begin{array}{l}\text { Abordar o eixo de formação pessoal e social do referencial } \\
\text { curricular nacional para a educação Infantil. }\end{array}$ \\
\hline $\begin{array}{l}\text { Referencial curricular nacional } \\
\text { para a Educação Infantil - Volume } \\
\text { III (BRASIL, 1998c) }\end{array}$ & $\begin{array}{l}\text { Abordar o eixo conhecimento de mundo do referencial nacional } \\
\text { curricular para a Educação Infantil. }\end{array}$ \\
\hline $\begin{array}{l}\text { Resolução CEB no. 2, de } 19 \text { de } \\
\text { abril de } 1999 \text { (BRASIL, 1999) }\end{array}$ & $\begin{array}{l}\text { Institui Diretrizes Curriculares Nacionais para a Formação de } \\
\text { Docentes da Educação Infantil e dos anos iniciais do Ensino } \\
\text { Fundamental, em nível médio, na modalidade Normal. }\end{array}$ \\
\hline $\begin{array}{l}\text { Resolução CNE/CEB n }{ }^{\circ} .02 \\
\text { (BRASIL, 2001) }\end{array}$ & $\begin{array}{l}\text { Institui Diretrizes Nacionais para a Educação Especial na } \\
\text { Educação Básica. }\end{array}$ \\
\hline $\begin{array}{l}\text { Resolução CNE/CP n }{ }^{\circ} .1 \text {, de } 18 \text { de } \\
\text { fevereiro de } 2002 \text { (BRASIL, 2002) }\end{array}$ & $\begin{array}{l}\text { Institui Diretrizes Curriculares Nacionais para a Formação de } \\
\text { Professores da Educação Básica, em nível superior, curso de } \\
\text { licenciatura, de graduação plena. }\end{array}$ \\
\hline $\begin{array}{l}\text { Política Nacional de Educação } \\
\text { Infantil: pelo direito da criança de } \\
\text { 0 a } 6 \text { anos à educação (BRASIL, } \\
\text { 2006a) }\end{array}$ & $\begin{array}{l}\text { Promover a inclusão, combater a miséria e colocar a educação } \\
\text { de todos no campo dos direitos. }\end{array}$ \\
\hline $\begin{array}{c}\text { Parâmetros básicos de } \\
\text { infraestrutura para instituições de } \\
\text { Educação Infantil (BRASIL, } \\
\text { 2006b) }\end{array}$ & $\begin{array}{l}\text { Oferecer orientações para planejar, refletir e } \\
\text { os espaços destinados à educação das crian }\end{array}$ \\
\hline $\begin{array}{l}\text { Parâmetros nacionais de qualidade } \\
\text { para a Educação Infantil - Volume } \\
\text { I (BRASIL, 2006c) }\end{array}$ & $\begin{array}{r}\text { Apresentar } \\
\text { ser }\end{array}$ \\
\hline $\begin{array}{l}\text { Parâmetros nacionais de qualidade } \\
\text { para a Educação Infantil - Volume } \\
\text { II (BRASIL, 2006d) }\end{array}$ & $\begin{array}{c}\text { Listar competências dos sistemas de ensino em níveis federal, } \\
\text { estadual e municipal. }\end{array}$ \\
\hline $\begin{array}{l}\text { Política Nacional de Educação } \\
\text { Especial na perspectiva da } \\
\text { Educação Inclusiva (BRASIL, } \\
\text { 2008) }\end{array}$ & $\begin{array}{c}\text { Garantir o acesso, a participação e a aprendizagem dos alunos } \\
\text { com deficiência, transtornos globais do desenvolvimento e altas } \\
\text { habilidades/superdotação nas escolas regulares, orientando os } \\
\text { sistemas de ensino para promover respostas às necessidades } \\
\text { educacionais especiais. }\end{array}$ \\
\hline $\begin{array}{l}\text { Resolução no . 4, de } 2 \text { de outubro de } \\
2009 \text { (BRASIL, 2009a) }\end{array}$ & $\begin{array}{c}\text { Institui Diretrizes Operacionais para o Atendimento } \\
\text { Educacional Especializado na Educação Básica, modalidade } \\
\text { Educação Especial. }\end{array}$ \\
\hline $\begin{array}{r}\text { Resolução no. 5, de } 17 \\
\text { de } 2009 \text { (BRASIL }\end{array}$ & $\begin{array}{c}\text { Fixar Diretrizes Curriculares Nacionais para a Educação } \\
\text { Infantil. Corresponde à atualização da Resolução CNE/CEB nº } \\
\text { 1, de } 7 \text { de abril de } 1999 .\end{array}$ \\
\hline
\end{tabular}

Fonte: Autoria própria 
No que se refere à concepção de desenvolvimento infantil presente nessas normativas, o Referencial Curricular Nacional para a Educação Infantil (RCNEI - BRASIL, 1998a) considera a criança enquanto um sujeito social e histórico e destaca as intrínsecas relações entre o desenvolvimento infantil e o meio social, com ênfase na família enquanto um ponto de referência fundamental. Concebe-se que as crianças são seres que sentem e pensam o mundo de um jeito peculiar, construindo o conhecimento a partir das interações que estabelecem com as outras pessoas e com o ambiente (BRASIL, 1998a).

Observa-se um viés interacionista, tanto na concepção de desenvolvimento e de infância quanto na concepção de aprendizagem expressas nos três volumes do RCNEI (BRASIL, 1998a; 1998b; 1998c). Esse viés interacionista também é expresso pela defesa da diversidade de parceiros e experiências enquanto potencializadora do desenvolvimento infantil. Assim, crianças expostas a múltiplas possibilidades interativas têm maiores oportunidades e condições para a construção de um repertório pessoal mais amplo (BRASIL, 2006c; 2006d).

A "Política Nacional de Educação Infantil: pelo direito da criança de 0 a 6 anos à educação" (BRASIL, 2006a) reconhece que essa concepção de infância e de desenvolvimento tem se modificado historicamente. Atualmente, vigora uma compreensão da criança como ser sócio histórico, criador, capaz de estabelecer múltiplas relações, sujeito de direitos, produtor de cultura e nela inserido. Essa concepção contribui para a definição das funções a serem cumpridas com as crianças, as quais envolvem dois aspectos indissociáveis: educar e cuidar.

Ainda no que se refere à concepção de desenvolvimento infantil, os "Parâmetros nacionais de qualidade para a Educação Infantil" (BRASIL, 2006c) reconhecem a ação da família e da comunidade enquanto primordial para o pleno desenvolvimento de crianças até 6 anos, defendendo o compartilhamento da responsabilidade familiar, comunitária e do poder público por esse desenvolvimento.

A família também é mencionada na Lei de Diretrizes e Bases da Educação Nacional (BRASIL, 1996), quando, em seu Artigo $1^{\circ}$, refere que os processos educacionais correspondem aos processos formativos que se desenvolvem desde a vida familiar, assim como na convivência humana, nas instituições de ensino e pesquisa, nos movimentos sociais e organizações da sociedade civil e nas manifestações culturais.

As DCNs para a Educação Infantil (BRASIL, 2009b) preconizam, em seu Art. $4^{\circ}$, que as propostas pedagógicas da Educação Infantil considerem a criança o centro do planejamento curricular, enquanto um sujeito histórico e de direitos que constrói sua identidade pessoal e 
coletiva por meio das interações, relações e práticas cotidianas que vivencia. Assim, idealiza uma criança que brinca, imagina, deseja, aprende, observa, experimenta, narra, questiona e constrói sentidos sobre a natureza e a sociedade.

\section{Quanto aos pressupostos legais para a implementação de práticas inclusivas na}

Educação Infantil, diversas normativas mencionam a necessidade de uma educação para todos, desde a Educação Infantil. O RCNEI (BRASIL, 1998a; 1998b; 1998c) refere que educar significa prover situações que integrem cuidados, brincadeiras e aprendizagens, de modo a contribuir para o estabelecimento de relações pautadas em atitudes de respeito e aceitação. Concebe como Escola Inclusiva aquela que dá espaço para todas as crianças, incluindo as nomeadas "com necessidades especiais". As escolas inclusivas têm o desafio, portanto, de desenvolver uma pedagogia centrada na criança, capaz de educar a todas, sem discriminação, respeitando suas diferenças, dando conta da diversidade e oferecendo respostas adequadas às suas características e necessidades, contanto, para isso, com o apoio de instituições e especialistas, quando necessário.

O RCNEI (BRASIL, 1998a; 1998b; 1998c) reconhece que a qualidade dessas práticas inclusivas depende da estrutura organizacional das instituições, pressupondo propostas que considerem: o grau de deficiência e as potencialidades de cada criança; a idade cronológica; a disponibilidade de recursos humanos e materiais existentes na comunidade; as condições socioeconômicas e culturais da região; e os serviços de educação especial implantados.

As "Diretrizes Nacionais para a Educação Especial na Educação Básica" (BRASIL, 2001a) pontuam que o ideário inclusivo implica mudanças significativas nas práticas educacionais, pois transfere a responsabilidade do aluno para a escola, ou seja, cabe às escolas proverem espaços acessíveis e condições de atendimento à diversidade manifestada. Concebe o processo de inclusão enquanto o provimento de acesso e permanência aos espaços de convivência em sociedade, acolhendo a diversidade e provendo oportunidades equitativas às pessoas (BRASIL, 2001a).

Essas Diretrizes nomeiam a Educação Especial como uma modalidade da educação escolar que deve assegurar um conjunto de recursos e serviços educacionais especializados e organizados institucionalmente, e estabelece os "serviços de apoio especializado" como estratégia para a implementação dessa modalidade. Tais serviços podem ser desenvolvidos:

a) Nas classes comuns, mediante atuação de professor da educação especial, de professores intérpretes das linguagens e códigos aplicáveis e de outros profissionais; itinerância intra e interinstitucional e outros apoios necessários à aprendizagem, à locomoção e à comunicação; b) Em salas de recursos, nas 
quais o professor da educação especial realiza a complementação e/ou suplementação curricular, utilizando equipamentos e materiais específicos. Caracterizam-se como serviços especializados aqueles realizados por meio de parceria entre as áreas de educação, saúde, assistência social e trabalho. (BRASIL, 2001a, p. 42-43)

É possível constatar o caráter eminentemente intersetorial almejado pelas práticas que se pretendem inclusivas, requerendo apoio multiprofissional das áreas da educação, da saúde e da assistência social, assim como apontado no trecho a seguir:

Há que se estabelecer um relacionamento profissional com os serviços especializados disponíveis na comunidade, tais como aqueles oferecidos pelas escolas especiais, centros ou núcleos educacionais especializados, instituições públicas e privadas de atuação na área da educação especial. Importante, também, é a integração dos serviços educacionais com os das áreas da saúde, trabalho e assistência social [...] (BRASIL, 2001a, p. 35-36)

Esse diálogo intersetorial também requer investimentos, visando a "[...] intensificação quantitativa e qualitativa na formação de recursos humanos e garantia de recursos financeiros e serviços de apoio pedagógico públicos e privados especializados para assegurar o desenvolvimento educacional dos alunos" (BRASIL, 2001a, p. 29-30).

Atualmente, vigora a "Política Nacional de Educação Especial na Perspectiva da Educação Inclusiva” (BRASIL, 2008), instituída com o objetivo de promover o acesso, a participação e a aprendizagem dos alunos com deficiência, transtornos globais do desenvolvimento e altas habilidades/superdotação nas escolas regulares, orientando os sistemas de ensino de modo a garantir: a transversalidade da educação especial desde a Educação Infantil até a educação superior; o Atendimento Educacional Especializado (AEE); a continuidade da escolarização nos níveis mais elevados do ensino; a formação de professores para o atendimento educacional especializado e demais profissionais da educação para a inclusão escolar; a participação da família e da comunidade; a acessibilidade urbanística, arquitetônica, nos mobiliários e equipamentos, nos transportes, na comunicação e informação; e a articulação intersetorial na implementação das políticas públicas.

No que diz respeito ao AEE na Educação Infantil, é especificado que, de 0 a 3 anos, o mesmo deve acontecer em serviços de estimulação precoce. Não é mencionado como devem ser ofertados os serviços para a população de 4 e 5 anos, pontuando-se apenas que o AEE apoie o desenvolvimento dos alunos em todas as etapas e modalidades da educação básica (BRASIL, 2008). A Resolução nº. 4, de 2 de outubro de 2009 (BRASIL, 2009a), institui diretrizes para o provimento de ações de educação especial na educação básica e também não 
faz menção específica à Educação Infantil, preconizando apenas a transversalidade das ações nos níveis, etapas e modalidades da educação básica.

Ainda no que se refere à Educação Inclusiva na Educação Infantil, o RCNEI (BRASIL, 1998a; 1998b; 1998c) destaca os benefícios da convivência com a diversidade para as crianças, nas instituições educativas, na potencialização dos aprendizados. Pelo viés das crianças com necessidades especiais, “[...] o convívio com as outras crianças também se torna benéfico na medida em que representa uma inserção de fato no universo social e favorece o desenvolvimento e a aprendizagem [...]" (BRASIL, 1998a, p. 35).

Ainda no que toca o provimento de Educação Inclusiva na Educação Infantil, algumas normativas abordam a questão da formação de professores, como é o caso da Resolução CEB $\mathrm{n}^{\text {o }}$ 2, de 19 de abril de 1999 (BRASIL, 1999). Esta resolução destaca que as escolas de formação de professores devem organizar propostas pedagógicas que preparem os docentes para diversas áreas de atuação, listando a Educação Infantil e a educação de "portadores" de necessidades educativas especiais como áreas específicas, simultâneas ou não. Da mesma forma, a Resolução CNE/CP n .1 , de 18 de fevereiro de 2002 (BRASIL, 2002), estabelece que a organização curricular de todas as instituições educacionais deve assegurar o preparo docente para, dentre outras coisas, o acolhimento e o trato da diversidade. Do mesmo modo, institui que a definição dos conhecimentos exigidos para a constituição de competências deverá contemplar conhecimentos sobre crianças, adolescentes, jovens e adultos, aí incluídas as especificidades dos alunos com necessidades educacionais especiais (BRASIL, 2002).

A partir das questões norteadoras deste estudo e dos objetivos elencados para responder às mesmas, considera-se que cabe discutir os resultados aqui apresentados a partir de três eixos.

O primeiro diz respeito à concepção de desenvolvimento infantil adotada nas normativas oficiais, que traduz uma perspectiva interacionista, o que permite uma discussão à luz da Teoria do Desenvolvimento Ocupacional, ancorada na crença de que o desenvolvimento humano é um desenvolvimento ocupacional, no qual as ocupações são responsáveis por proporcionar mudanças progressivas no aprendizado e no desempenho ocupacional. Considerando que as aquisições no desenvolvimento ocorrem a partir do aprendizado e do desempenho de ocupações, o desenvolvimento infantil pode ser caracterizado pelo aprendizado, periódico e de progressiva complexidade, de ocupações (PRIECE; STEPHENSON, 2009; EMMEL, 2015). 
Assim, o desenvolvimento é compreendido como os processos de "[...] mudança gradual nos comportamentos ocupacionais ao longo do tempo e resulta do crescimento e da maturação da pessoa em interação com o ambiente" (CAOT, 1997, p. 40).

O comportamento ocupacional infantil resulta da interação entre criança-ambienteocupação, em um processo dinâmico e complexo, de vivências e oportunidades para constituir um conjunto de ocupações que fazem parte da vida de uma pessoa em determinado momento, denominado de repertório ocupacional (NJELESANI et al., 2017).

As ocupações infantis podem ser entendidas, portanto, como ações intencionais que as crianças realizam no curso de seu desenvolvimento. Na medida em que se envolvem em ocupações com a família, amigos ou outras pessoas, desenvolvem seus papéis enquanto criança que brinca, que estuda, que se relaciona com outras pessoas e que cuida de si mesma (MANDICH; RODGER, 2006).

Defende-se que este referencial contempla a necessidade de apropriação dos estudos e pesquisas sobre ocupações infantis, de modo que se possa desenvolver, cada vez mais, intervenções pautadas na atenção integral à criança e sua família (NUCCI et al., 2017), considerando os contextos por elas frequentados, dentre eles, a escola.

O segundo engendra a necessidade de articulação intersetorial para o provimento de práticas inclusivas na Educação Infantil. A busca pela implementação de práticas intersetoriais já é esboçado em documentos sobre a atenção integral à criança e em algumas políticas de saúde (BRASIL, 2016; INOJOSA, 2001). Porém, no âmbito das políticas educacionais, especificamente as normativas da Educação Infantil, embora seja feita menção em algumas, ainda é escassa a previsão de ações e estratégias que caracterizem a materialização da integralização entre os setores saúde, educação e assistência social.

As normativas preconizam que a Educação Infantil seja estruturada a partir de dois vieses principais: o educar e o cuidar. Tendo estas duas funções, o trabalho pedagógico visa atender às necessidades específicas da faixa etária. Concorda-se, portanto, com Kramer (2000), ao defender:

[...] uma concepção de criança que reconhece o que é específico da infância - seu poder de imaginação, fantasia, criação - e entende as crianças como cidadãs, pessoas que produzem cultura e são nela produzidas, que possuem um olhar crítico que vira pelo avesso a ordem das coisas, subvertendo essa ordem (p. 5). 
A Política Nacional de Educação Infantil (BRASIL, 2006a) reconhece o desafio imposto à promoção de práticas que integrem o cuidar e o educar. Campos e Rosemberg (2009) consideram essa integração um dos critérios de qualidade da Educação Infantil.

Assim, atenta-se para a necessidade de um trabalho intersetorial entre saúde-educaçãoassistência para o provimento de práticas no âmbito da Educação Infantil. As normativas reconhecem que o cuidado ultrapassa a esfera pedagógica e requer a integração de outros campos de conhecimento:

Contemplar o cuidado na esfera da instituição da educação infantil significa compreendê-lo como parte integrante da educação, embora possa exigir conhecimentos, habilidades e instrumentos que extrapolam a dimensão pedagógica. Ou seja, cuidar de uma criança em um contexto educativo demanda a integração de vários campos de conhecimentos e a cooperação de profissionais de diferentes áreas (BRASIL, 1998a, p. 24).

A previsão de diálogo com serviços de saúde abre possibilidades para uma investida intersetorial, como refere o trecho a seguir:

A atenção à saúde das crianças é um aspecto muito importante do trabalho em instituições de educação infantil. [...] A responsabilidade da instituição de educação infantil nesses aspectos é muito grande. É desejável que a equipe conte com uma competente orientação sobre as condutas adequadas para cada grupo de idade. E que tenha também um bom contato com os serviços de saúde mais próximos, além de manter abertos os canais de comunicação com as famílias para melhor atuar em relação a problemas de saúde que possam ocorrer com as crianças e para se informar sobre as necessidades individuais que elas apresentam (BRASIL, 2009b, p. 48).

Além dessas normativas, estudos mencionam que, para um trabalho efetivo na interface cuidado-educação, não basta contemplar as práticas de cuidado, sendo necessária uma equipe de apoio que possa dar suporte aos processos educacionais desenvolvidos na esfera da atenção integral à primeira infância (DELLA BARBA; MARTINEZ; CARRASCO, 2003; MARTINEZ et al., 2016; NUCCI et al., 2017; JURDI; TEIXEIRA; SÁ, 2017).

O terceiro refere-se às considerações acerca do que é preconizado nas normativas para o provimento de práticas inclusivas na Educação Infantil, pois apesar de apontarem pressupostos de boas práticas para a efetivação da inclusão, muitas vezes não são mencionadas estratégias para essa implementação. Os documentos em geral pouco falam sobre a diversidade e o respeito às diferenças, exceto quando são documentos específicos acerca da Educação Inclusiva. Em Campos e Rosemberg (2009) e nos Parâmetros básicos de 
infraestrutura para instituições de educação infantil (BRASIL, 2006b), não há qualquer destaque para o Público-Alvo da Educação Especial (PAEE) e sequer são previstas adequações dos espaços para este público.

Somente as normativas que falam sobre educação inclusiva abordam as questões das deficiências, o que revela que Educação Infantil e Educação Inclusiva ainda são tratadas de forma dicotômica, deixando a critério do executor da política a interpretação da lei, o que prejudica a garantia dos pressupostos para a inclusão. Estudos anteriores já apontaram essas questões e reforçam a necessidade de que a discussão da Educação Inclusiva seja transversal às políticas educacionais como um todo (MENDES, 2010; GARCIA, 2004).

Sabe-se que a efetivação da educação inclusiva não se efetuará por decreto. É necessário avaliar as reais condições que possibilitem a inclusão e planejar gradativa e continuamente a inserção e o acompanhamento de alunos com necessidades educacionais especiais nos sistemas de ensino (BRASIL, 2001a).

\section{Considerações finais}

Este estudo teve como objetivos analisar as normativas oficiais brasileiras alusivas à Educação Infantil, no que se refere à concepção de desenvolvimento infantil adotada e aos pressupostos para o provimento de práticas inclusivas neste nível educacional, assim como discutir os pressupostos legais para a implementação de práticas inclusivas na Educação Infantil, segundo as normativas oficiais brasileiras.

Foi possível observar a forte presença de uma perspectiva interacionista do desenvolvimento infantil, coerente com uma perspectiva teórica que concebe o desenvolvimento humano enquanto um desenvolvimento ocupacional. Sugerem-se benefícios da adoção dessa perspectiva ocupacional para o desenvolvimento de práticas educacionais condizentes com o que é preconizado nas normativas oficiais brasileiras.

Também foi observada uma forte necessidade de articulação intersetorial para o provimento satisfatório de condições suficientes para a inclusão educacional de todas as crianças na Educação Infantil. Essa premissa é apontada em algumas normativas, porém ainda aparece desvinculada das estratégias de ação que são pontuadas nas mesmas.

Do mesmo modo, constatou-se que as normativas oficiais sobre Educação Infantil e Educação Inclusiva, embora possam ser relacionadas, ainda evidenciam dicotomias e possibilidade de várias interpretações. Sugere-se a necessidade de oficialização das intrínsecas 
relações entre estas duas temáticas, a fim de garantir a implementação de práticas inclusivas desde a Educação Infantil.

As limitações do estudo estão relacionadas à ausência de alguns documentos oficiais que listam prescrições para a Educação Infantil brasileira, o que se justifica pelo não atendimento aos objetivos deste estudo. Sugere-se que outros estudos possam ser realizados, ampliando a amostra dos documentos analisados, assim como envolvendo outros eixos de análise, para além da concepção de desenvolvimento infantil e das prescrições para a educação inclusiva na educação infantil.

\section{REFERÊNCIAS}

BRASIL. Estatuto da Criança e do Adolescente. Lei no 8.069, de 13 de julho de 1990. Dispõe sobre o Estatuto da Criança e do Adolescente e dá outras providências. 1990.

BRASIL. Ministério da Educação e do Desporto. Lei n 9.394, de 20 de dezembro de 1996. Institui as Diretrizes e Bases para a Educação Nacional. 1996.

BRASIL. Ministério da Educação e do Desporto. Secretaria de Educação Fundamental. Referencial curricular nacional para a educação infantil. Volume I. Brasília: MEC/SEF, 1998a.

BRASIL. Ministério da Educação e do Desporto. Secretaria de Educação Fundamental. Referencial curricular nacional para a educação infantil. Volume II. Brasília: MEC/SEF, 1998b.

BRASIL. Ministério da Educação e do Desporto. Secretaria de Educação Fundamental. Referencial curricular nacional para a educação infantil. Volume III. Brasília: MEC/SEF, 1998c.

BRASIL. Ministério da Educação. Política Nacional de Educação Especial na perspectiva da Educação Inclusiva. 2008.

BRASIL. Ministério da Educação. Resolução CNE/CEB n ${ }^{\circ}$ 02/2001. Institui as Diretrizes Nacionais para a Educação Especial na educação Básica. 2001 a.

BRASIL. Ministério da Educação. Resolução CNE/CP 1, de 18 de fevereiro de 2002.

BRASIL. Ministério da Educação. Resolução no 4, de 2 de outubro de 2009. Institui Diretrizes Operacionais para o Atendimento Educacional Especializado na Educação Básica, modalidade Educação Especial. 2009a.

BRASIL. Ministério da Educação. Resolução n 5, de 17 de dezembro de 2009. Fixa as Diretrizes Curriculares Nacionais para a Educação Infantil. 2009b. 
BRASIL. Ministério da Educação. Secretaria de Educação Básica. Política Nacional de Educação Infantil: pelo direito da criança de 0 a 6 anos à educação. 2006a.

BRASIL. Ministério da Educação. Secretaria de Educação Básica. Parâmetros básicos de infraestrutura para instituições de educação infantil. Brasília: MEC, SEB, 2006b.

BRASIL. Ministério da Educação. Secretaria de Educação Básica. Parâmetros nacionais de qualidade para a educação infantil. Volume I. Brasília, 2006c.

BRASIL. Ministério da Educação. Secretaria de Educação Básica. Parâmetros nacionais de qualidade para a educação infantil. Volume II. Brasília, 2006d.

BRASIL. Presidência da República. Lei no 7.853 de 24 de outubro de 1989.

BRASIL. Lei no 13.257 de 8 de março de 2016. Dispõe da Lei do Marco Legal para a Primeira Infância.

CAMPOS, M. M. A educação infantil frente a seus desafios. Fundação Carlos Chagas. Difusão de Ideias, 2009.

CAMPOS, M. M.; ROSEMBERG, F. Critérios para um atendimento em creches que respeite os direitos fundamentais das crianças. 6.ed. Brasília: MEC, SEB, 2009.

CAOT - Canadian Association of Occupational Therapy. Enabling occupation: an occupational therapy perspective, 1997.

DELLA BARBA, P. C. S.; MARTINEZ, C. M. S.; CARRASCO, B. G. Promoção da saúde e educação infantil: caminhos para o desenvolvimento. Paidéia, Ribeirão Preto, v. 13, n. 26, p. 141-146, 2003.

DUNFORD, C.; BANNIGAN, K. Children and young people's occupations, health and well being: a research manifesto for developing the evidence base, World Federation of Occupational Therapists Bulletin, v. 64, n. 1, p. 46-52, 2011.

EMMEL, M. L. Desenvolvimento Ocupacional da criança. In: JOAQUIM, R. H.; DELLA BARBA, P.; ALBUQUERQUE, I. (Orgs). Desenvolvimento da criança de zero à seis anos e a Terapia Ocupacional. São Carlos: EdUFSCar, 2015. (Série Apontamentos), p. 39-48.

FRANCISCHINI, R.; SILVA, C. V. M. O surgimento da educação infantil na história das políticas públicas para a criança no Brasil. Práxis Educacional, v. 8, n. 12, p. 257-276, 2012.

GARCIA, R. M. C. Políticas públicas de inclusão: uma análise no campo da educação especial brasileira. 2004. 227f. Tese (Doutorado em Educação) - Programa de Pós-Graduação em Educação, Centro de Ciências da Educação, Universidade Federal de Santa Catarina. Florianópolis, 2004.

INOJOSA, R. M. Sinergia em políticas e serviços públicos: desenvolvimento social com intersetorialidade. Cadernos Fundap, n. 22, 102-110, 2001. 
JURDI, A. P. S.; TEIXEIRA, P. A.; SÁ, C. S. C. Vulnerabilidade socioambiental e o cuidado na primeira infância: o olhar da terapia ocupacional para o trabalho em creche. Rev Ter Ocup Univ São Paulo, v. 28, n. 3, p. 281-9, 2017.

KUHLMANN JR, M. Histórias da educação infantil brasileira. Revista Brasileira de Educação, n. 14, p. 5-18, 2000.

MANDICH, A.; RODGER, S. Doing, being and becoming: their importance for children. In: RODGER, S.; ZIVIANI, J. Occupational Therapy with children: understanding children's occupations and enabling participation. Malden: Blackwell Publishing, 2006. p. 115-135.

MARTINEZ, C. M. S. et al. Redes de colaboração e intersetorialidade nas creches públicas do estado de São Paulo. Cad. Ter. Ocup. UFSCar, v. 24, n. 4, p. 673-680, 2016.

MENDES, E. G. Inclusão Marco Zero: começando pelas creches. Araraquara: Junqueira e Marin, 2010.

NJELESANI, J. et al. Test Construction of the Occupational Repertoire Development Measure-Parent (ORDM-P). American Journal of Occupational Therapy, v. 71, 2017.

NUCCI, L. V. et al. Produção de conhecimento em Terapia Ocupacional na perspectiva da atenção integral à criança. Revista Interinstitucional Brasileira de Terapia Ocupacional, v. 1, p. 693-703, 2017.

OLIVEIRA, M. I. Educação Infantil: legislação e prática pedagógica. Psic. da Ed., São Paulo, 27, p. 53-70, 2008.

PRIECE, P.; STEPHENSON, S. Learning to promote occupational development through cooccupation. Journal of Occupational Science. Vol. 16 (3). p. 180-186, 2009.

\section{Como referenciar este artigo}

FOLHA, Débora Ribeiro da Silva Campos.; RAMOS, Maysa Marinho Antunes.; DELLA BARBA, Patrícia Carla de Souza. Normativas oficiais para a Educação Infantil brasileira: desenvolvimento infantil e efetivação da educação inclusiva. Revista Ibero-Americana de Estudos em Educação, Araraquara, v. 14, n. esp. 1, p. 671-685, abr., 2019. E-ISSN: 19825587. DOI: 10.21723/riaee.v14iesp.1.12198

Submetido em: 06/08/2018

Aprovado em: 21/09/2018 